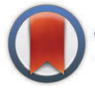

CrossMark \& click for updates

Cite this: J. Mater. Chem. C, 2016, 4, 4296

Received 4th February 2016 Accepted 21st March 2016

DOI: $10.1039 / c 6 t c 00531 d$

www.rsc.org/MaterialsC

\title{
Thiazole-based scaffolding for high performance solar cells $\dagger$
}

\author{
I. Bulut, ${ }^{a}$ P. Chávez, ${ }^{a}$ A. Mirloup, ${ }^{b}$ Q. Huaulmé, ${ }^{b}$ A. Hébraud, ${ }^{a}$ B. Heinrich, ${ }^{c}$ S. Fall, ${ }^{d}$ \\ S. Méry, ${ }^{c}$ R. Ziessel, ${ }^{b}$ T. Heiser, ${ }^{d}$ P. Lévêque ${ }^{\star d}$ and N. Leclerc*a
}

\begin{abstract}
An interesting way of decreasing both $\mathrm{HOMO}$ and LUMO energy levels simultaneously while keeping the band-gap constant in soluble electron-donor small molecules for photovoltaic applications is presented. This consists in the replacement of thiophene rings by thiazole units in small molecules based on the alternation of electron-rich and electron-deficient moieties. A new diketopyrrolopyrrole-based dumbbellshaped electron-donor soluble molecule for organic photovoltaic applications has been synthesized and characterized. It includes thiazole units as linkers between the bis-lactam core and the triazatruxene moieties used as $\pi$-stacking platforms. A power conversion efficiency of $6.3 \%$ has been attained with this thiazole derivative and in particular with an increase of the open-circuit voltage of $0.15 \mathrm{~V}$ with respect to the thiophene-based organic semiconducting counterpart. This open-circuit voltage increase is due to the lowering of the HOMO level of the thiazole derivative while its LUMO level has also been stabilized as highlighted by the similar band-gap measured for the thiazole and thiophene derivatives.
\end{abstract}

\section{Introduction}

During the past decade, the use of organic molecules for photovoltaic applications has been spotlighted, thanks to the engineering of original chemical structures possessing suitable optoelectronic properties, reaching efficiencies of over $10 \%{ }^{1}$ Many prerequisites are required to reach the optimal conditions for efficient organic photovoltaic (OPV) cells. In particular, (i) a broad absorption range is required to maximize the harvesting of incident solar photons, (ii) the frontier energy levels have to be adjusted in such a way that a deep HOMO level (highest occupied molecular orbital) allows an increase in the open

\footnotetext{
${ }^{a}$ Institut de Chimie et Procédés pour l'Energie, l'Environnement et la Santé (ICPEES), Département d'Ingénierie Polymère, UMR 7515 Université de Strasbourg-CNRS, 25 rue Becquerel, Strasbourg 67087, France. E-mail: leclercn@unistra.fr

${ }^{b}$ Institut de Chimie et Procédés pour l'Energie, l'Environnement et la Santé (ICPEES), Laboratoire de Chimie Moléculaire et Spectroscopies Avancées,

UMR 7515 Université de Strasbourg-CNRS, 25 rue Becquerel, Strasbourg 67087, France

${ }^{c}$ Institut de Physique et Chimie des Matériaux de Strasbourg (IPCMS), UMR 7504 Université de Strasbourg-CNRS, 23 rue du Loess, Strasbourg 67034, France

${ }^{d}$ Laboratoire des Sciences de l'ingénieur, de l'informatique et de l'imagerie (ICube), UMR 7357 Université de Strasbourg-CNRS, 23 rue du Loess, Strasbourg 67037, France. E-mail: patrick.leveque@unistra.fr

$\dagger$ Electronic supplementary information (ESI) available: Experimental techniques, synthesis and characterization of the dyes (Fig. S1-S12), absorption and emission spectra (Fig. S13-S15), redox potentials (Table S1), thermogravimetric and DSC analyses (Fig. S16 and S17), SAXS and GIWAXS spectra (Fig. S18-S20), AFM images (Fig. S21) and the EQE spectrum (Fig. S22). See DOI: 10.1039/c6tc00531d
}

circuit voltage $\left(V_{\text {oc }}\right)$, while a relatively high LUMO level (lowest unoccupied molecular orbital) provides an accurate driving force for efficient exciton dissociation and charge separation and finally, (iii) strong intermolecular interactions in the solid state will be highly suitable for exciton diffusion and for charge carrier mobility affecting both the short circuit current density $\left(J_{\mathrm{sc}}\right)$ and the fill factor $(\mathrm{FF})$.

In light of these requirements, the engineering of electronic energy levels appears to be one of the key parameters to increase the power conversion efficiency (PCE) of OPV devices. Unfortunately, decreasing the band-gap often conflicts with the lowering of the HOMO level. Ideally, both the HOMO and LUMO energy levels should be simultaneously decreased in order to increase the $V_{\mathrm{oc}}$ while keeping the band-gap constant. Such a fine energy level tuning is chemically challenging and, to the best of our knowledge, few successful approaches have been reported to date in the literature. The most common approach consists in the selective replacement of some hydrogen atoms along the conjugated backbone by fluorine atoms. Indeed, fluorine atoms act as small electron-withdrawing groups that allow a simultaneous decrease of both energy levels by about $0.15 \mathrm{eV}$. This strategy has been successfully applied to several conjugated polymers and small molecules, leading to highly efficient photovoltaic devices. ${ }^{2}$ Another method consists in the use of thioalkyl chains instead of standard alkyl side chains to bring solubility. Such a substitution has shown a weak lowering of the LUMO and a stronger lowering of the HOMO energy levels leading to higher $V_{\mathrm{oc}}{ }^{3}$

In this paper, we report an alternative and efficient chemical approach to lower both frontier energy levels, based on the use 
of thiazole rings as weak electron-donor species. Indeed, due to its more electron-deficient nature with regard to a standard thiophene ring, we recently demonstrated that the introduction of a thiazole unit into an alternating electron-rich/electron-poor conjugated backbone appears therefore as a convenient and effective way to increase both the ionization potential and electron affinity by about 0.1 to $0.2 \mathrm{eV}$, when compared to the thiophene unit, while keeping the energy band-gap almost unchanged. ${ }^{4}$ However, a positive impact of this approach on the open-circuit voltage and power conversion efficiency has only been rarely properly demonstrated in an organic photovoltaic device ${ }^{5}$ even though the thiazole unit was previously used in semiconducting polymers. $^{6}$

Therefore, we applied this chemical strategy to a small molecule in which a thiazole-substituted diketopyrrolopyrrole (TzDPP) unit is sandwiched between two triazatruxene (TAT) moieties to form a dumbbell-shaped molecular structure. We indeed recently demonstrated that such a construct, with thiophene-substituted diketopyrrolopyrrole (ThDPP), behaves as an efficient electron-donor when blended with phenyl-C71butyric acid methyl ester $\left(\mathrm{PC}_{71} \mathrm{BM}\right)$, leading to a high PCE in solution-processed small molecule-based OPV devices. ${ }^{7}$ The DPP core is seen as a bis-lactam unit sandwiched by two aromatic substituents at the 3 and 6 positions. These two substituents behave as electron-rich $\pi$-conjugated linkers and can be easily functionalized. The modification of these linkers usually leads to a significant change in the physical and optoelectronic properties (crystal structure, thermal transitions, band gap, HOMO-LUMO levels, etc.) of DPP-based materials. ${ }^{8}$ Based on this knowledge, the synthesis and characterization of a new TAT-DPP small molecule derivative containing thiazole linking units between the DPP core and the peripheral TAT units (TAT-TzDPP in Fig. 1) is reported herein. We demonstrate, in particular, that these thiazole linkers allow a significant increase, in the $V_{\text {oc }}$, allowing the PCE of bulk heterojunction devices to reach $6.3 \%$.

\section{Experimental section}

\section{Synthesis}

General procedure. All reagents and chemicals were purchased from commercial sources. THF and toluene were distilled from $\mathrm{Na}$ /benzophenone. 2-Bromothiazole, tris(o-methoxyphenyl)phosphine and other reagents and chemicals were used as received. DPP-Tz, ${ }^{6 c}$ trans-di( $\mu$-acetato)bis $[o$-(di-o-tolyl-phosphino)benzyl]dipalladium(II), ${ }^{9} \mathrm{Pd}\left(\mathrm{PPh}_{3}\right)_{4}$ and TAT(H) ${ }^{7}$ were prepared as described in the literature.

${ }^{1} \mathrm{H}$ and ${ }^{13} \mathrm{C}$ NMR spectra were recorded on $300 \mathrm{MHz}$ and $400 \mathrm{MHz}$ NMR spectrometers, with ${ }^{1} \mathrm{H}$ and ${ }^{13} \mathrm{C}$ chemical shifts reported in $\delta$ (ppm) relative to $\mathrm{CDCl}_{3}$ (7.26 and 77.16, respectively). MS (EI) and HRMS experiments were performed on a Bruker spectrometer within the service center at the "Institut de Chimie" of Strasbourg University.

5,10,15-Trihexyl-10,15-dihydro-5 $H$-diindolo[3,2-a:3' $\mathbf{2}^{\prime}$-c $]$ carbazole: TAT $\left(\mathbf{C}_{\mathbf{6}}\right)$. A flame-dried Schlenk flask was charged with 10,15-dihydro-5 $H$-diindolo[3,2- $a: 3^{\prime}, 2^{\prime}$-c $]$ carbazole (1.0 equiv.), $\mathrm{NaH}$ (60\% in mineral oil) (7.0 equiv.) and dried DMF/THF $(50 / 50)(0.1 \mathrm{M})$. The mixture was stirred for $30 \mathrm{~min}$ at room temperature. Then, 1-bromohexyl (7.0 equiv.) was added dropwise under inert gas. The mixture was heated at $70{ }^{\circ} \mathrm{C}$ overnight. After cooling to room temperature the reaction mixtures were evaporated under reduced pressure and purified first by extraction with water and $\mathrm{CH}_{2} \mathrm{Cl}_{2}$, the organic phase was dried over $\mathrm{MgSO}_{4}$ and concentrated under reduced pressure. The final purification was carried out by chromatography on flash silica as a static phase with a mixture of petroleum ether/ $\mathrm{CH}_{2} \mathrm{Cl}_{2}(95 / 5)$ as a mobile phase to give $\mathbf{T A T}\left(\mathbf{C}_{6}\right)$ as the
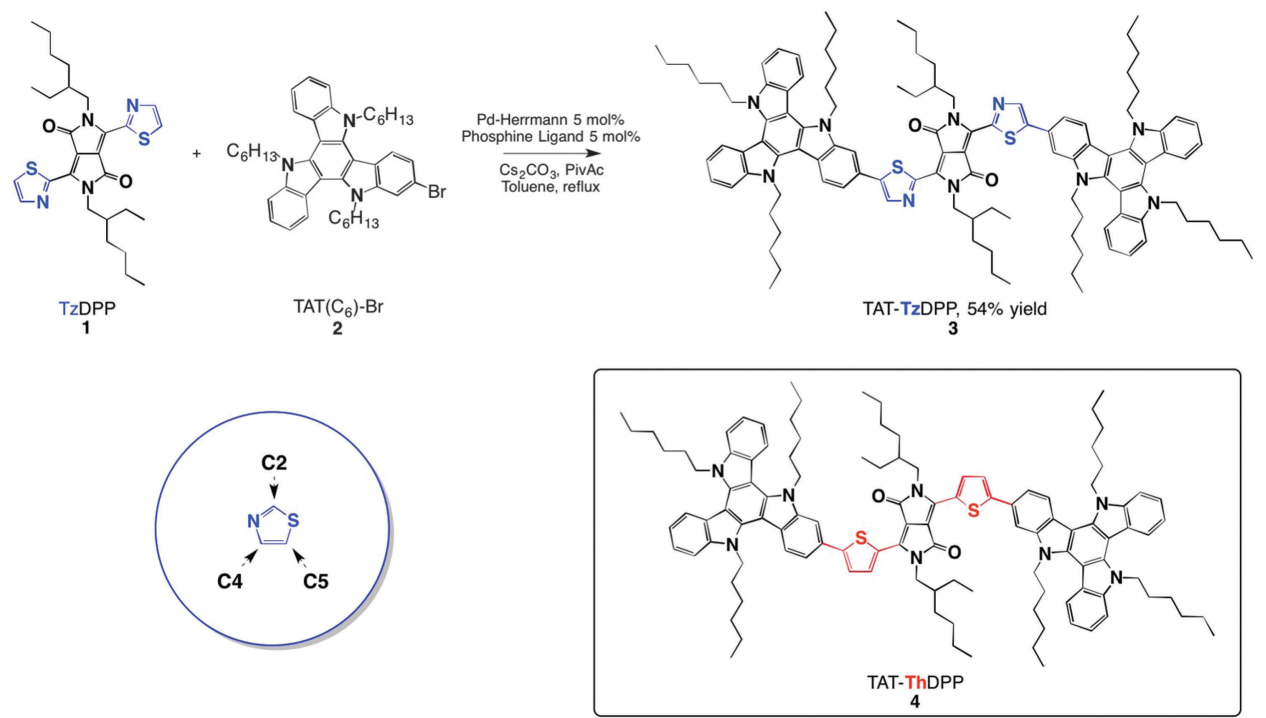

Fig. 1 Synthetic route towards the preparation of the TAT-TzDPP dye. The left inset depicts the thiazole nomenclature. The right inset shows the reference TAT-ThDPP molecule used for reference. ${ }^{7}$ 
desired product. mol. wt: $597.87 \mathrm{~g} \mathrm{~mol}^{-1}$. White solid. Yield 95\%. ${ }^{1} \mathrm{H}$ NMR $\left(300 \mathrm{MHz}, \mathrm{CDCl}_{3}\right) \delta(\mathrm{ppm})=8.29(\mathrm{~d}, J=7.9 \mathrm{~Hz}$, $3 \mathrm{H}), 7.63(\mathrm{~d}, J=7.8 \mathrm{~Hz}, 3 \mathrm{H}), 7.45(\mathrm{t}, J=7.2 \mathrm{~Hz}, 3 \mathrm{H}), 7.34(\mathrm{t}, J=$ $7.2 \mathrm{~Hz}, 3 \mathrm{H}), 4.93(\mathrm{t}, J=7.8 \mathrm{~Hz}, 6 \mathrm{H}), 1.98-1.96(\mathrm{~m}, 6 \mathrm{H}), 1.26-1.23$ $(\mathrm{m}, 18 \mathrm{H}), 0.81(\mathrm{~m}, 9 \mathrm{H}) .{ }^{13} \mathrm{C} \mathrm{NMR}\left(75 \mathrm{MHz}, \mathrm{CDCl}_{3}\right) \delta(\mathrm{ppm})=$ 141.1, 138.9, 123.6, 122.7, 121.5, 119.6, 110.5, 103.3, 47.1, 31.4, 29.7, 26.3, 22.4, 13.8. HRMS ESI-TOF $\mathrm{m} / \mathrm{z}$ (\%) calculated for [M] $\mathrm{C}_{42} \mathrm{H}_{51} \mathrm{~N}_{3}$ 597.4078; found 597.4082.

2-Bromo-5,10,15-trihexyl-10,15-dihydro-5 $H$-diindolo[3,2-a:3' $\mathbf{2}^{\prime}$ c]carbazole: 2-BrTAT( $\left.\mathbf{C}_{6}\right)$ (2). TAT( $\left.\mathbf{C}_{6}\right)$ (1.0 equiv.) was dissolved in $\mathrm{CHCl}_{3} / \mathrm{DMF}$ (90/5) (0.1 M) and placed in a dark Schlenk flask. Then, NBS was added portion-wise and the reaction was monitored using TLC. The solution was quenched with $\mathrm{H}_{2} \mathrm{O}$ and the organic phases were extracted with $\mathrm{CHCl}_{3}$, dried over $\mathrm{MgSO}_{4}$ and concentrated under reduced pressure. The purification was carried out by chromatography on flash silica as a static phase with a mixture of petroleum ether/toluene (95/5) as a mobile phase and afforded 2-BrTAT(C $\left.\mathbf{C}_{6}\right)$ (2). mol. wt: $676.77 \mathrm{~g} \mathrm{~mol}^{-1}$. White solid. Yield 60\%. ${ }^{1} \mathrm{H}$ NMR $\left(300 \mathrm{MHz}, \mathrm{CDCl}_{3}\right) \delta(\mathrm{ppm})=8.31(\mathrm{~m}, 2 \mathrm{H}), 8.03$ $(\mathrm{d}, J=8.8 \mathrm{~Hz}, 1 \mathrm{H}), 7.70(\mathrm{~s}, 1 \mathrm{H}), 7.64(\mathrm{~m}, 2 \mathrm{H}), 7.51(\mathrm{~m}, 5 \mathrm{H}), 4.88(\mathrm{~m}$, 6H), 1.95 (s, 6H), 1.29 (m, 18H), $0.92(\mathrm{~m}, 9 \mathrm{H}) .{ }^{13} \mathrm{C}$ NMR (75 MHz, $\left.\mathrm{CDCl}_{3}\right) \delta(\mathrm{ppm})=142.1,141.2,139.2,139.1,138.7,123.5,123.4$, 123.1, 122.7, 122.6, 121.7, 121.6, 119.9, 116.2, 113.5, 110.7, 103.7, 103.3, 102.9, 47.1, 31.5, 29.8, 26.4, 22.6, 14.0. MS ESI-TOF $m / z(\%)$ calculated for $[\mathrm{M}] \mathrm{C}_{42} \mathrm{H}_{50} \mathrm{BrN}_{3}$ : 675.3227(100), 676.3258(20), 677.3171(100), 678.3236(20); found 677.3217 (100), 676.3258(20), 675.3227 (100), 678.3236(20).

2,5-Bis(2-ethylhexyl)-3,6-bis(5-(5,10,15-trihexyl-10,15-dihydro$5 H$-diindolo[3,2-a:3' $2^{\prime}$-c] carbazol-2-yl)thiazol-2-yl)pyrrolo[3,4-c]pyrrole-1,4(2H,5H)-dione: TAT-TzDPP (3). A flame dried Schlenk flask was charged with 2,5-bis(2-ethylhexyl)-3,6-di(thiazol-2-yl)pyrrolo[3,4-c]pyrrole-1,4(2H,5H)-dione (1.0 equiv.), Pd-Herrmann (0.05 equiv.), ligand: tris( $o$-methoxyphenyl)phosphine (0.05 equiv.), $\mathrm{Cs}_{2} \mathrm{CO}_{3}$ (2.5 equiv.) and PivAc (0.35 equiv.). Dried and degassed toluene $(0.2 \mathrm{M})$ was added under inert gas followed by $\mathbf{T A T}\left(\mathbf{C}_{\mathbf{6}}\right)-\mathbf{B r}$ (2.2 equiv.) and the mixture was stirred for $14 \mathrm{~h}$ at $120{ }^{\circ} \mathrm{C}$. After cooling to room temperature the reaction mixtures were evaporated under reduced pressure and purified first by column chromatography (silica gel, $\mathrm{CH}_{2} \mathrm{Cl}_{2}$ /petroleum ether: 40/60) and finally by recrystallization in $\mathrm{CH}_{2} \mathrm{Cl}_{2} / \mathrm{EtOH}$. mol. wt: $1718.47 \mathrm{~g} \mathrm{~mol}^{-1}$. Dark blue solid. Yield 54\%. ${ }^{1} \mathrm{H}$ NMR $\left(400 \mathrm{MHz}, \mathrm{CDCl}_{3}\right) \delta(\mathrm{ppm})=8.34(\mathrm{~s}, 1 \mathrm{H}), 8.24-8.34(\mathrm{~m}, 3 \mathrm{H})$, $7.89(\mathrm{~d}, J=1.5 \mathrm{~Hz}, 1 \mathrm{H}), 7.67(\mathrm{dd}, J=1.6,7.7 \mathrm{~Hz}, 1 \mathrm{H}), 7.64$ (dd, $J=4.9,7.9 \mathrm{~Hz}, 2 \mathrm{H}), 7.47(\mathrm{t}, J=7.6 \mathrm{~Hz}, 2 \mathrm{H}), 7.32-7.48$ $(\mathrm{m}, 2 \mathrm{H}), 5.00(\mathrm{t}, J=7.6 \mathrm{~Hz}, 2 \mathrm{H}), 4.89-4.92(\mathrm{~m}, 4 \mathrm{H}), 1.95-2.02$ $(\mathrm{m}, 7 \mathrm{H}), 1.20-1.49(\mathrm{~m}, 27 \mathrm{H}), 1.01-0.92(\mathrm{~m}, 6 \mathrm{H}), 0.86-0.78$ $(\mathrm{m}, 9 \mathrm{H}) .{ }^{13} \mathrm{C}$ NMR $\left(101 \mathrm{MHz}, \mathrm{CDCl}_{3}\right) \delta(\mathrm{ppm})=161.4,153.0$, $146.0,141.5$, 141.2, 141.1, 140.0, 139.6, 139.5, 138.5, 137.3, $124.9,124.7,123.4,123.4,123.0(\times 2), 121.9,121.6(\times 2)$ $119.9,119.8,119.5,110.6,110.5,108.9,103.8,103.4,47.1$ $(\times 2), 46.8,39.5,31.4,31.3,31.3,30.7,29.7,29.6,29.6,28.7$, 26.3, 26.3, 26.2, 24.1, 23.1, 22.4, 22.3, 22.3, 14.0, 13.8, 13.7, 10.8. HRMS ESI-TOF $m / z(\%)$ calculated for $[\mathrm{M}] \mathrm{C}_{112} \mathrm{H}_{136} \mathrm{~N}_{10} \mathrm{O}_{2} \mathrm{~S}_{2}$ : 1718.0315; found: 1718.0316. Elemental analysis theoretical values: $\% \mathrm{~N} 8.15, \% \mathrm{C} 78.28, \% \mathrm{H} 7.98$, found values: $\% \mathrm{~N} 8.11$, $\% \mathrm{C} 78.25, \% \mathrm{H} 7.95$.

\section{UV-visible spectroscopy and luminescence spectroscopy}

UV-visible spectra were recorded using a Shimadzu UV-3600 dualbeam grating spectrophotometer with a $1 \mathrm{~cm}$ quartz cell. Steadystate emission and excitation spectra were recorded at $25{ }^{\circ} \mathrm{C}$ on a HORIBA Jobin-Yvon FluoroMax 4P spectrofluorimeter. All fluorescence spectra were corrected. The fluorescence quantum yield was calculated using the following equation:

$$
\Phi_{\mathrm{F}_{\mathrm{cmpd}}}=\Phi_{\mathrm{F}_{\mathrm{ref}}} \frac{I_{\mathrm{cmpd}}\left[1-\exp \left(-A_{\mathrm{cmpd}} \ln 10\right)\right] n^{2}}{I_{\mathrm{ref}}\left[1-\exp \left(-A_{\text {ref }} \ln 10\right)\right] n_{\mathrm{ref}^{2}}}
$$

where $I$ denotes the integral of the corrected fluorescence spectrum, $A$ is the absorbance at the excitation wavelength and $n$ is the refractive index of the medium. Luminescence lifetimes were measured on a FL 920 Edinburgh Instruments spectrofluorimeter equipped with a R928 photomultiplier and a PicoQuant PDL 800-D pulsed diode connected to a $\mathrm{G}^{\mathrm{w}}$ Instect GFG-8015G delay generator. Emission wavelengths were selected using a monochromator. Luminescence lifetimes were measured on a spectrofluorimeter using software with Time-Correlated Single Photon Mode coupled to a stroboscopic system. The excitation source was a laser diode $(\lambda=310 \mathrm{~nm})$. No filter was used for excitation. The instrument response function was determined by using a light-scattering solution (LUDOX).

\section{Electrochemical measurements}

Oxidation and reduction potentials were determined by cyclic voltammetry with a conventional 3-electrode system using a voltammetric analyzer equipped with a platinum micro disk $\left(2 \mathrm{~mm}^{2}\right)$ working electrode and a platinum wire counter electrode. Potentials were calibrated versus the saturated calomel electrode (SCE) using the ferrocene/ferricinium couple as an internal reference $(+0.38 \mathrm{~V}$ vs. SCE $)$ at a conventional scan rate of $200 \mathrm{mV} \mathrm{s}^{-1}$. Recrystallized tetrabutylammonium hexafluorophosphate $\left(\mathrm{Bu}_{4} \mathrm{NPF}_{6}\right)$ was used as the supporting electrolyte $(0.1 \mathrm{M})$ in distilled and anhydrous $\mathrm{CH}_{2} \mathrm{Cl}_{2} \cdot \mathrm{CH}_{2} \mathrm{Cl}_{2}$ was distilled from $\mathrm{P}_{2} \mathrm{O}_{5}$ under a nitrogen atmosphere. The ferrocene/ferricinium couple was used as an internal reference.

\section{DSC measurements}

DSC measurements were performed using a TA Instruments Q1000 instrument, operated at a scanning rate of $5{ }^{\circ} \mathrm{C} \mathrm{min}^{-1}$ upon heating and upon cooling.

\section{Results and discussion}

The starting building block $\mathbf{1}^{6 c}$ (Fig. 1) was prepared and purified according to the literature procedure. The synthesis of 2-bromo-TAT (2) is detailed in the Experimental section. The nature of this 2-bromo-TAT (2) isomer has been unambiguously assigned by reference to the 3-bromo-TAT isomer synthesized by an independent protocol (see the ESI $\dagger$ supported by Fig. S1 to S10).

To synthesize the TAT-TzDPP dye (3), an original and selective direct arylation cross-coupling was preferred to the standard Suzuki cross-coupling previously used for the thiophene derivative. ${ }^{7}$ This cleaner and atom-economical cross-coupling 
reaction has been carried out between compounds 1 and 2 in the presence of the palladium-Herrmann catalyst, phosphine ligand $\left[\mathrm{P}\left(p-\mathrm{MeOC}_{6} \mathrm{H}_{4}\right)_{3}\right], \mathrm{Cs}_{2} \mathrm{CO}_{3}$ as a base and pivalic acid as an additive, leading to the target TAT-TzDPP compound (3) with $54 \%$ yield after purification. This catalyst system makes this cross-coupling reaction highly regioselective taking place selectively in the C5-position of the thiazole unit. ${ }^{4 b, 10}$

The NMR spectral analysis of the final TAT-TzDPP molecule shows only one singlet peak at $8.30 \mathrm{ppm}$, which is assigned to the thiazole proton in the C4-position, in agreement with previous studies (Fig. S11). ${ }^{4 b, 11}$ The only by-product of this condensation reaction that has been isolated is the mono-coupling compound. This direct arylation cross-coupling appears even more efficient if we consider that the dibromination of the TzDPP derivative is often described with reaction yields of only 20-30\% after purification. ${ }^{5,6 b}$ All compounds were characterized by standard NMR and mass spectrometry.

The electronic spectra (absorption and emission) of the new DPP dye are shown in Fig. 2 and Fig. S13 (ESI $\dagger$ ). The absorption spectrum of TAT-TzDPP in solution shows an intense peak at around $657 \mathrm{~nm}\left(\varepsilon=85000 \mathrm{M}^{-1} \mathrm{~cm}^{-1}\right)$ corresponding to the lowest energy $\pi-\pi^{*}$ transitions $\left(\mathrm{S}_{0} \rightarrow \mathrm{S}_{1}\right)$ of the DPP chromophore. ${ }^{13,14}$ The marked shoulder at higher energy of this intense absorption is typical of the vibronic sequence $\left(\Delta \nu=1230 \mathrm{~cm}^{-1}\right)$ of a bis-lactam framework. ${ }^{15}$ Another weaker transition at ca. $500 \mathrm{~nm}$ is likely due to an internal charge transfer (ICT) transition in keeping with previous observations. ${ }^{16,17}$ The strong transition recorded at about $320 \mathrm{~nm}(\varepsilon=130000$ to $180000 \mathrm{M}^{-1} \mathrm{~cm}^{-1}$ ) is assigned to $\pi-\pi^{*}$ transitions of the fused tris-carbazole platform. ${ }^{18}$ The dye fluorescence observed in THF shows a maximum emission at about $757 \mathrm{~nm}$. The emission profile (Fig. S13, ESI $\dagger$ ) does not mirror the absorption one, indicating a polarized excited state typical of a charge transfer state. A large Stokes shift of $2000-3900 \mathrm{~cm}^{-1}$ and a short lifetime (about $2 \mathrm{~ns}$ ) also confirm the emission from a charge transfer state. ${ }^{13,14}$

The quantum yield is rather weak (3\%). The emission band is slightly broader and the excited state lifetime drops down to $0.55 \mathrm{~ns}$ and the emission properties show a high solvent polarity sensitivity (Fig. S14, ESI $\dagger$ ). Interestingly, by decreasing

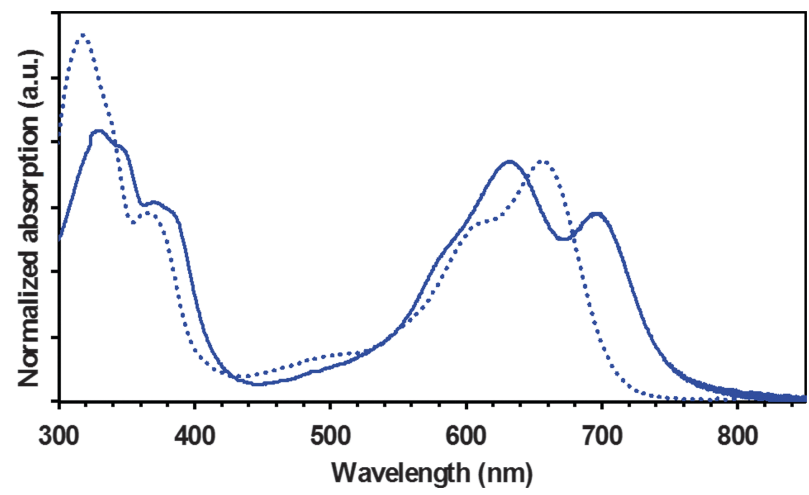

Fig. 2 Normalized absorption in solution (dashed lines) and in thin-film (full lines) of TAT-TzDPP. the dipole moment of the solvent (from THF to toluene) the intensity of the emission band of TAT-TzDPP increases as well as the corresponding excited state lifetime (QY from 3\% to 46\%, lifetime from 0.55 to $3.06 \mathrm{~ns}$ ). The sensitivity of the emission to the polarity of the solvent is in favor of an ICT-like emission. ${ }^{13,14}$

The thin film absorption spectrum (full line in Fig. 2) shows a significant bathochromic shift in comparison to its solution counterpart due to stronger intermolecular interactions in the solid state. The amplitude shift is roughly $40 \mathrm{~nm}$ from the band edge. From the solid-state absorption onset, an optical gap of $1.65 \mathrm{eV}$ has been calculated for TAT-TzDPP.

The cyclic voltammetry in dilute solution allows for the determination of the frontier molecular orbital energies (HOMO/LUMO levels) after calibration with ferrocene used as an internal reference. The voltammogram (Fig. 3) displays several well-defined and reversible waves, which can be assigned, by comparison with reference to isolated synthons, to the constitutive molecular modules of the compound. As previously observed, the TAT fragment is not electroactive in the anodic window, whereas the DPP moieties display two reversible reduction waves (Fig. 3). ${ }^{13,14}$

The first reduction wave is located at $-0.93 \mathrm{~V}$. Note that most of the redox processes appear to be reversible $\left(i_{\mathrm{pa}} / i_{\mathrm{pc}} \approx 1\right)$ and exhibit the characteristic shape $\left(\Delta E_{\mathrm{p}}=60-70 \mathrm{mV}\right)$ of a Nernstian, one-electron process. The second reduction wave is located at -1.49 V. Each reduction is monoelectronic and according to previous reports, the reduction processes are assigned to the formation of the radical anion and dianion of the substituted bislactam central core. ${ }^{13,16}$ The positive potential region is much richer and shows several oxidation waves.

The TAT substrate exhibits three reversible monoelectronic oxidations in the +0.50 to $+1.40 \mathrm{~V}$ potential range (Fig. 3), in agreement with the literature data, ${ }^{7,16}$ while the TzDPP core exhibits one reversible oxidation wave, located at $+0.67 \mathrm{~V}$. The electrochemical gap, deduced from the HOMO/LUMO level positions, is $1.60 \mathrm{eV}$ and this value is in line with the optical gap reported above (Table 1). Electrochemical data are summarized in Table $\mathrm{S} 1$ in the ESI. $\dagger$

At this stage it is worth pointing out the large difference in frontier orbital energies observed between the TzDPP-based

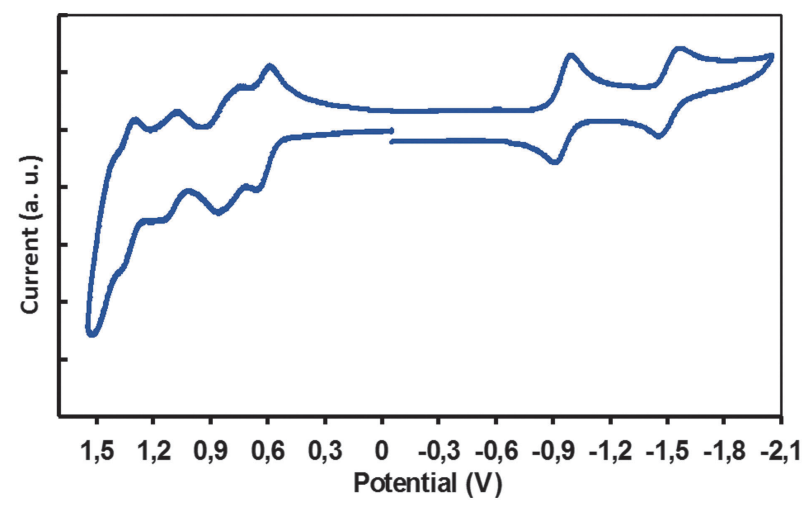

Fig. 3 Cyclic voltammogram in dichloromethane for TAT-TzDPP using $\mathrm{TBAPF}_{6}$ as the supporting electrolyte. 
Table 1 Spectroscopic data for TAT-TzDPP measured in THF at room temperature ${ }^{a}$

\begin{tabular}{|c|c|c|c|c|c|c|c|c|c|}
\hline \multicolumn{8}{|l|}{ Solution } & \multicolumn{2}{|l|}{ Thin film } \\
\hline$\lambda_{\mathrm{abs}}(\mathrm{nm})$ & $\varepsilon\left(\mathrm{M}^{-1} \mathrm{~cm}^{-1}\right)$ & $\lambda_{\mathrm{em}}(\mathrm{nm})$ & $\Phi @ \lambda_{\mathrm{ex}},(\mathrm{nm})$ & $\tau(\mathrm{ns})$ & $K_{\mathrm{p}}^{b}\left(10^{8} \mathrm{~s}^{-1}\right)$ & $k_{\mathrm{nr}}^{c}\left(10^{8} \mathrm{~s}^{-1}\right)$ & $\Delta_{\mathrm{ss}}\left(\mathrm{cm}^{-1}\right)$ & $\lambda_{\mathrm{abs}}(\mathrm{nm})$ & $\Delta E_{\mathrm{g}}(\mathrm{eV})$ \\
\hline 657 & 85000 & 757 & 0.03@600 & 0.55 & 0.55 & 17.6 & 2000 & 695 & 1.65 \\
\hline
\end{tabular}

compound and the previously reported thiophene derivative (see the structure in the inset of Fig. 1), despite their similar absorption properties (see Fig. S15, ESI, $\dagger$ for solid state absorption comparison). ${ }^{7}$ Indeed, the oxidation and reduction potentials measured for TAT-TzDPP are consistently up-shifted in comparison with TAT-ThDPP $\left[E_{\text {oxy }}=+0.47 \mathrm{~V}\right.$ and $\left.E_{\text {red }}=-1.24 \mathrm{~V}\right] .^{7}$ As a result, both HOMO and LUMO energy levels of the thiazole derivative are significantly down-shifted by around $0.20 \mathrm{eV}$ with regard to the thiophene derivative. By considering that the opencircuit voltage $\left(V_{\text {oc }}\right)$ of an organic photovoltaic device is strongly dependent on the offset between the LUMO level of the electron acceptor and the HOMO level of the electron donor, ${ }^{19}$ we may expect a higher $V_{\text {oc }}$ when the TAT-TzDPP dye is used as the electron donor, keeping almost constant the photon harvesting properties for both TAT-TzDPP and TAT-ThDPP dyes. We note that the offset between the LUMO of the electron-donor molecule and the LUMO of the electron acceptor $\mathrm{PC}_{71} \mathrm{BM}$ (measured under the same conditions at $-4.20 \mathrm{eV})^{7}$ is equal to $350 \mathrm{meV}$ for TAT-TzDPP. This offset should be sufficient for efficient charge separation. ${ }^{20}$

Thermal properties have been characterized by differential scanning calorimetry (DSC) and thermal gravimetric analysis (TGA). Both materials exhibit a remarkable thermal stability with degradation temperatures above $300{ }^{\circ} \mathrm{C}$ (Fig. S16, ESI $\dagger$ ). Unlike a recent series of amorphous TAT-based systems bearing ramified chains, ${ }^{21}$ the face-to-face close packing of TAT segments is here authorized by the less sterically demanding linear chains. It then allows the self-organization of the dye in various structures delaying the phase transition toward the isotropic liquid to $240-270{ }^{\circ} \mathrm{C}$ (see DSC in Fig. S17, ESI $\dagger$ ). Despite the similar shape of conjugated moieties and the identical peripheral chains, the self-organization behavior of TAT-TzDPP turns out to be different from the previously reported TAT-ThDPP. ${ }^{7}$ The latter dye is a semi-crystalline solid as deduced from optical polarizing microscopy (POM) and confirmed by powder smallangle X-ray scattering (SAXS) analyses (see Fig. S18, ESI $\dagger$ ). In contrast, TAT-TzDPP is mesomorphous and gives rise to birefringent (but not-characteristic) POM textures that progressively become fluid upon heating. A columnar mesophase-like piling is confirmed by SAXS, as a semi-diffuse peak $h_{\mathrm{TAT}}$ at $3.8 \AA$ from distances between piled TAT segments (correlation length $\xi \approx 5 \mathrm{~nm}$ upon cooling from $110{ }^{\circ} \mathrm{C}$ ) overlaps the broad wideangle scattering $h_{\mathrm{ch}, \mathrm{Tz}}$ at around $4.5 \AA$ from liquid-like lateral distances between chains and thiazole linkers (see Fig. S18 and S19, ESI $\dagger$ ). In the small-angle range a somewhat broadened reflection $D_{\text {TAT }}$ at $17.6 \AA$ arises from the arrangement of TAT piles separated from each other by the undifferentiated continuum formed by disordered chains and linkers. The structure however deviates from a genuine columnar mesophase as the linking units introduce a three-dimensional geometrical character and a structural disorder, which explains the reduced correlation length $(\xi \approx 13 \mathrm{~nm})$ and the unresolved higher order reflections. In this view, the mesomorphism of TAT-TzDPP appears to be the consequence of the absence of self-organization of the thiazole segments that prevents the crystallization of the whole molecule.

Charge transport properties have been determined in organic field effect transistor (OFET) devices with a bottom contactbottom gate configuration. Details of the OFET device fabrication can be found in the ESI. $\dagger$ The output and transfer FET characteristics for as-cast TAT-TzDPP can be seen in Fig. 4. The hole mobility was extracted in the saturation regime using the standard formalism. This value is reasonably high, in the order of $3.8 \times 10^{-3} \mathrm{~cm}^{2} \mathrm{~V}^{-1} \mathrm{~s}^{-1}$ for TAT-TzDPP, and should be compared with the previously reported mobility of the thiophene analogue (TAT-ThDPP, $4.4 \times 10^{-4} \mathrm{~cm}^{2} \mathrm{~V}^{-1} \mathrm{~s}^{-1}$ ). ${ }^{7}$

We note a substantially higher in-plane hole mobility for the mesomorphic TAT-TzDPP compared to the crystalline compound. Hole-only devices with an ITO/PEDOT:PSS/small molecule/ $\mathrm{MoO}_{3} / \mathrm{Ag}$ structure were elaborated to estimate the out-of-plane hole mobility in the space charge limited current (SCLC) regime. Details of the SCLC device fabrication as well as the $(I-V)$ characteristics for two different TAT-TzDPP thicknesses can be found in the ESI. $\dagger$ The out-of-plane hole mobility was estimated to be as
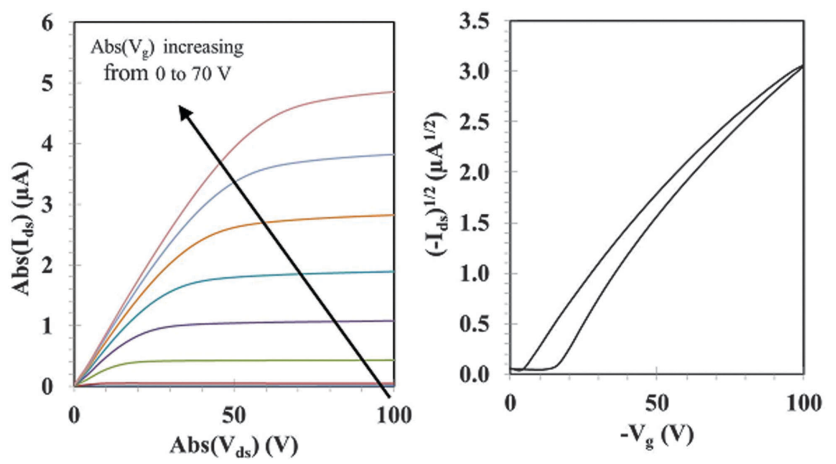

Fig. 4 Output characteristics (left) and transfer characteristics (right) of an as-cast TAT-TzDPP OFET. For the output characteristics, the gate voltage $\left(V_{\mathrm{g}}\right)$ is increased from 0 to $-70 \mathrm{~V}$ with a $-10 \mathrm{~V}$ step. For the transfer characteristics in the saturation regime, the drain-source voltage $\left(V_{\text {ds }}\right)$ is set at $-100 \mathrm{~V}$ and $V_{\mathrm{g}}$ is varied from 0 to $-100 \mathrm{~V}$. 
high as $3.7 \times 10^{-2}$ and $1.5 \times 10^{-3} \mathrm{~cm}^{2} \mathrm{~V}^{-1} \mathrm{~s}^{-1}$ for TAT-ThDPP and TAT-TzDPP, respectively. For TAT-TzDPP, the out-of-plane hole mobility is lower than the in-plane hole mobility as expected from the dependence of the mobility as a function of the charge carrier concentration. ${ }^{22}$ On the other hand, the out-of-plane hole mobility is almost two orders of magnitude higher than the in-plane hole mobility for TAT-ThDPP, suggesting a high chargetransport anisotropy for this crystalline compound. ${ }^{22}$

Organic photovoltaic (OPV) devices were elaborated using both a standard and an inverted device architecture. For the standard architecture (anode on the transparent side of the device) the following layer sequence was used: ITO/PEDOT:PSS/ active layer/Ca/Al. For the inverted architecture (cathode on the transparent side of the device), the recently reported $80 \%$ ethoxylated polyethylenimine (PEIE) was used as the interface layer. ${ }^{23}$ The use of a thin layer of this polymer having pendant alkylamine groups is known to reduce the work function of ITO and can be processed in air from non-toxic alcoholic solutions. A reflective $\mathrm{MoO}_{3} / \mathrm{Ag}$ electrode has been used to collect holes on the top surface of the device. In all the cases, the active layers were made up of blends of TAT-based molecular compounds and $\mathrm{PC}_{71} \mathrm{BM}$ and were deposited by spin-coating from chloroform solutions. Thermal annealing at $120{ }^{\circ} \mathrm{C}$ for 10 minutes was performed before $\mathrm{Ca} / \mathrm{Al}$ or $\mathrm{MoO}_{3} / \mathrm{Ag}$ evaporation. Each OPV device consists of four diodes, each of them having an active area of $12 \mathrm{~mm} .^{2}$ Each condition has been tested at least twice. Other details of OPV device fabrication can be found in the ESI. $\dagger$

Electrical parameters of OPV devices are summarized in Table 2. Note that the standard deviations as well as the averaged PCE reported values were calculated from 6 to 10 diodes on different substrates elaborated under the same conditions. The fact that the best results were obtained on a standard architecture for TAT-ThDPP and on an inverted one for TAT-TzDPP is not clear at this stage and is still under investigation.

The main trends that can be drawn from the photovoltaic properties meet our predictions. First of all, the lowest open circuit voltage $\left(V_{\text {oc }}\right)$ values are found for the TAT-ThDPP compound which is in agreement with its higher lying HOMO level. ${ }^{19}$ Second, the short-circuit current density $\left(J_{\mathrm{sc}}\right)$, which depends in part on the absorption range of the compounds, is found to be similar in both thiophene and thiazole derivatives. As expected from the almost identical molecular shapes, the dye: $\mathrm{PC}_{71} \mathrm{BM}$ ratios needed to optimize the device performance are of $1: 0.75$ for both derivatives. This observation suggests that the different structural features between both derivatives do not affect their intermixing process with $\mathrm{PC}_{71} \mathrm{BM}$ and thus the percolation pathways for electron transport. ${ }^{24}$
The best photovoltaic performances were measured on TATTzDPP devices that combine a high $V_{\text {oc }}$ value (in the $0.7-0.8 \mathrm{~V}$ range) because of their low lying HOMO level, with a high $J_{\mathrm{sc}}$ value (more than $13 \mathrm{~mA} \mathrm{~cm}^{-2}$ ) due to their moderate optical band-gap (1.65 eV) and a high FF value of around 59\%.

Consequently, when we compare the best TAT-ThDPP photovoltaic results (in the standard structure) with the best TAT-TzDPP photovoltaic results (in the inverted structure), the thiazole-compound devices exhibit a comparable $J_{\mathrm{sc}}\left(13.2 \mathrm{~mA} \mathrm{~cm}^{-2}\right.$ and $14.4 \mathrm{~mA} \mathrm{~cm}^{-2}$ for TAT-ThDPP) value but a substantially higher $V_{\mathrm{oc}}$ value $(0.80 \mathrm{~V}$ and $0.63 \mathrm{~V}$ for TAT-ThDPP). Consequently, with a FF in the same range for both compounds (slightly below $60 \%$ ), the average power conversion efficiency is increased from $5.2 \%$ to $6.1 \%$ when $\mathrm{Tz}$ is used in the electrondonor small molecule.

Though the size of the statistical samples is limited (10 diodes for each best condition), the conclusion drawn here is unambiguous as the relative $V_{\text {oc }}$ increase (more than 25\%) when using Tz instead of Th is significantly higher than the standard deviation of the measured $V_{\mathrm{oc}}$ values (Table 2). A maximum PCE of $6.3 \%$ $\left(V_{\mathrm{oc}}=0.79 \mathrm{~V} ; J_{\mathrm{sc}}=13.3 \mathrm{~mA} \mathrm{~cm} \mathrm{~cm}^{2} ; \mathrm{FF}=60 \%\right)$ has been reached with TAT-TzDPP against $5.3 \%$ for TAT-ThDPP. The $(J-V)$ curves for the best photovoltaic devices using TAT-ThDPP and TAT-TzDPP are shown in Fig. 5. It can be noticed that in both cases, the best results were obtained without the help of additives.

Investigations of the optimized thin-film morphology of the new compound TAT-TzDPP in blend with $\mathrm{PC}_{71} \mathrm{BM}$ have been carried out by means of GIWAXS measurements. In the case of TAT-TzDPP, GIWAXS patterns (see Fig. 6 and S20) show, for a ratio of $1: 0.75$ with $\mathrm{PC}_{71} \mathrm{BM}$, a clear phase segregation of both components with the coexistence of mesomorphous TAT-TzDPP domains and amorphous $\mathrm{PC}_{71} \mathrm{BM}$ domains. It can be noticed that the preferential $\pi$-stacking direction is parallel to the meridian, which is favorable for a $\pi$-stacking charge transport perpendicular to the substrate plane.

The investigation of the active layer surface morphology of a TAT-TzDPP : PC $_{71} \mathrm{BM}$ blend (an optimal photovoltaic ratio of $1: 0.75)$ by dynamic amplitude modulation atomic force microscopy (tapping mode) under ambient conditions showed a smooth surface (peak/valley roughness below $7 \mathrm{~nm}$ ), with a slight domain size increase after thermal annealing (around $40 \mathrm{~nm}$ on average, see Fig. S21, ESI $\dagger$ ). The latter could lead to a more efficient bicontinuous interpenetrating network in thermally annealed active layers with regard to as-deposited thin films.

The external quantum efficiency (EQE) of one TAT-TzDPP device is shown in Fig. S24 (ESI $\dagger$ ). The difference between the $J_{\text {sc }}$ calculated from the EQE spectrum and the $J_{\mathrm{sc}}$ measured

Table 2 Average photovoltaic parameters measured under AM1.5G $\left(100 \mathrm{~mW} \mathrm{~cm}^{-2}\right)$ illumination

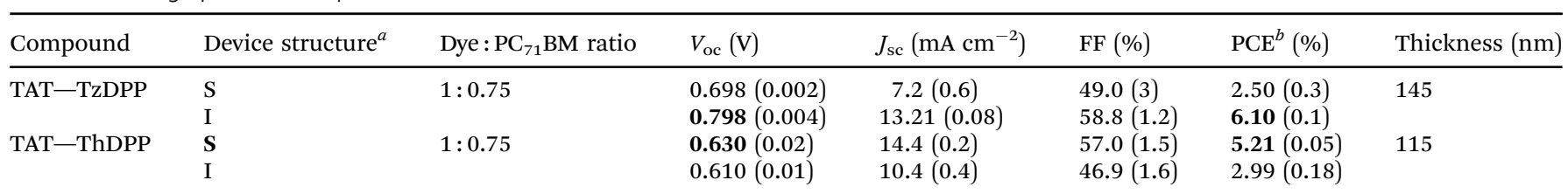

${ }^{a} \mathrm{~S}$ for standard and I for inverted. ${ }^{b}$ The standard deviation for each parameter is provided in parentheses. 


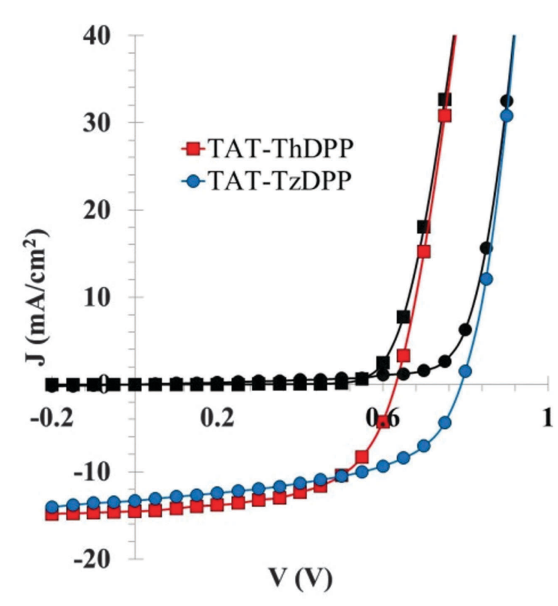

Fig. $5(J-V)$ curves obtained in the dark (black symbols) and under standard AM1.5G (100 mW cm${ }^{-2}$ ) illumination conditions (colored symbols). The squares correspond to the TAT-ThDPP compound (standard architecture) and the circles to the TAT-TzDPP compound (inverted architecture).

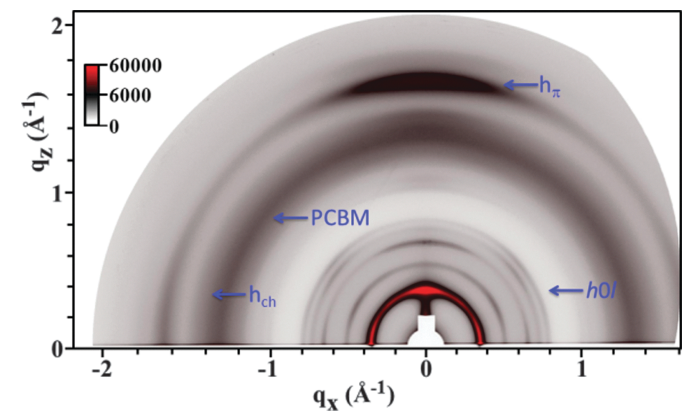

Fig. 6 GIWAXS pattern of TAT-TzDPP: $\mathrm{PC}_{71} \mathrm{BM}$ (ratio of $1: 0.75$ ) recorded after annealing at $120{ }^{\circ} \mathrm{C}$ for $10 \mathrm{~min}$.

under standard AM1.5G $\left(100 \mathrm{~mW} \mathrm{~cm}^{-2}\right)$ on the same device is below the measurement error margin (less than 5\%). As the EQE measurements are performed at significantly lower light intensity, this result indicates that the charge carrier recombination rate does not depend significantly on the light intensity in this device. Moreover, the EQE spectrum exhibits values above $60 \%$ over a broad spectral range (580-700 $\mathrm{nm}$ ), which is comparable with the state-of-the-art small molecule based solar cells. ${ }^{25}$

\section{Conclusions}

In summary, we have designed and synthesized a soluble small molecule engineered from a combination of diketopyrrolopyrrole (DPP) and triazatruxene (TAT) moieties for use in organic photovoltaic solar cells. We have demonstrated that the thiazole unit could be used efficiently as an alternative to the thiophene unit in an electron-donor molecule. In particular, we have shown that replacing a thienyl ring by a thiazole is an effective approach to stabilizing both HOMO and LUMO levels while keeping the initial photon harvesting properties of the organic semiconducting materials unchanged. A maximum PCE of $6.3 \%$ has thus been reached using a thiazole-based molecule and in particular with an increase of the $V_{\text {oc }}$ of $0.15 \mathrm{~V}$ with respect to the thiophene counterparts. Thiazole was until now mainly identified as an interesting electron deficient moiety, leading to efficient electron acceptor organic semiconducting materials. ${ }^{26}$ The present result highlights that the thiazole ring also constitutes a good candidate for building efficient electron donor organic semiconducting (macro)molecules for OPV. Finally, the high potential of this emerging DPP/aryl/TAT family of molecules for solution-processed BHJ solar cells was confirmed and further structural modifications in combination with other highly light-harvesting units are currently ongoing in our research laboratories.

\section{Acknowledgements}

Ibrahim Bulut and Patricia Chávez contributed equally to this work. This work was supported by the Interreg IV-A program under RhinSolar project (nr C25) and the French National Research Agency (ANR ORION project ANR-13-PRGE-0001). Elsa Cece, Dr Thomas Bura and Nicolas Zimmermann are acknowledged for the preparation of some of these compounds and devices. We thank the Pohang Accelerator Laboratory (PAL) for giving us the opportunity to perform the GIWAXS measurements, MEST and POSTECH for supporting these experiments, Drs Tae Joo Shin and Hyungju Ahn for adjustments and help, and other colleagues from the 9A USAXS beamline for assistance. Dr P. Montgomery is acknowledged for his careful reading of the manuscript and his suggestions for the English spelling. This research was supported by Leading Foreign Research Institute Recruitment Program through the National Research Foundation of Korea (NRF) funded by the Ministry of Science, ICT \& Future Planning (NRF-2010-00453).

\section{References}

1 (a) A. Mishra and P. Bäuerle, Angew. Chem., Int. Ed., 2012, 51, 2020; (b) P. M. Beaujuge and J. M. J Fréchet, J. Am. Chem. Soc., 2011, 133, 20009; (c) B. Kan, M. Li, Q. Zhang, F. Liu, X. Wan, Y. Wang, W. Ni, G. Long, X. Yang, H. Feng, Y. Zuo, M. Zhang, F. Huang, Y. Cao, T. P. Russell and Y. Chen, J. Am. Chem. Soc., 2015, 137, 3886.

2 (a) D. Dang, W. Chen, R. Yang, W. Zhu, W. Mammo and E. Wang, Chem. Commun., 2013, 49, 9335; (b) J. Wolf, F. Cruciani, A. El Labban and P. M. Beaujuge, Chem. Mater., 2015, 27, 4184; (c) P. Yang, M. Yuan, D. F. Zeigler, S. E. Watkins, J. A. Lee and C. K. Luscombe, J. Mater. Chem. C, 2014, 2, 3278; (d) N. Leclerc, P. Chávez, O. A. Ibraikulov, T. Heiser and P. Lévêque, Polymers, 2016, 8, 11.

3 (a) K. Feng, X. Xu, Z. Li, Y. Li, K. Li and T. Yu, Chem. Commun., 2015, 51, 6290; (b) C. Cui, W.-Y. Wong and Y. Li, Energy Environ. Sci., 2014, 7, 2276; (c) C. Cui, X. Guo, J. Min, B. Guo, X. Cheng, M. Zhang, C. J. Brabec and Y. Li, Adv. Mater., 2015, 27, 7469; (d) C. Cui, Z. He, Y. Wu, X. Cheng, H. Wu, Y. Li, Y. Cao and W.-Y. Wong, Energy Environ. Sci., 2016, 9, 885.

4 (a) E. Zaborova, P. Chávez, R. Bechara, P. Lévêque, T. Heiser, S. Méry and N. Leclerc, Chem. Commun., 2013, 49, 9938; 
(b) P. Chávez, C. Ngov, P. De Frémont, P. Lévêque and N. Leclerc, J. Org. Chem., 2014, 79, 10179.

5 J.-L. Wang, Z. Wu, J.-S. Miao, K.-K. Liu, Z.-F. Chang, R.-B. Zhang, H.-B. Wu and Y. Cao, Chem. Mater., 2015, 27, 4338.

6 (a) H. Bronstein, E. Collado-Fregoso, A. Hadipour, Y. Soon, Z. Huang, S. D. Dimitrov, R. Shahid Ashraf, B. P. Rand, S. E. Watkins, P. S. Tuladhar, I. Meager, J. R. Durrant and I. McCulloch, Adv. Funct. Mater., 2013, 23, 5647; (b) W. Li, K. H. Hendriks, A. Furlan, M. M. Wienk and R. A. J. Janssen, J. Am. Chem. Soc., 2015, 137, 2231; (c) B. Carsten, J. M. Szarko, L. Lu, H. J. Son, F. He, Y. Y. Botros, L. X. Chen and L. Yu, Macromolecules, 2012, 45, 6390.

7 T. Bura, N. Leclerc, R. Bechara, P. Lévêque, T. Heiser and R. Ziessel, Adv. Energy Mater., 2013, 3, 1118.

8 J. Dhar, N. Venkatramaiah, A. Anitha and S. Patil, J. Mater. Chem. C, 2014, 2, 3457.

9 W. A. Herrmann, C. Brossmer, K. Öfele, C.-P. Reisinger, T. Priermeier, M. Beller and H. Fischer, Angew. Chem., Int. Ed. Engl., 1995, 34, 1844.

10 S. Tani, T. N. Uehara, J. Yamaguchi and K. Itami, Chem. Sci., 2014, 5, 123.

11 A. K. Palai, S. P. Mishra, A. Kumar, R. Srivastava, M. N. Kamalasanan and M. Patri, Eur. Polym. J., 2010, 46, 1940.

12 J. Olmsted, J. Phys. Chem., 1979, 83, 2581.

13 (a) A. Iqbal and L. Cassar, US Pat., 4, 415, 685, Nov 15, 1983; (b) J. Pfenninger, A. Iqbal and A. C. Rochat, Eur. Pat., 184-981, June 18, 1986; (c) M. Jost, A. Iqbal and A. C. Rochat, Eur. Pat., 224-445, June 3, 1987.

14 D. Hablot, P. Retailleau and R. Ziessel, Chem. - Eur. J., 2010, 6, 13346.

15 A. Iqbal, M. Jost, R. Kirchmayr, J. Pfenninger, A. C. Rochat and O. Wallquist, Bull. Soc. Chim. Belg., 1988, 97, 615.
16 L. Dou, W.-H. Chang, J. Gao, C.-C. Chen, J. You and Y. Yang, Adv. Mater., 2013, 25, 825.

17 A. Sutter, P. Retailleau, W.-C. Huang, H.-W. Lin and R. Ziessel, New J. Chem., 2014, 38, 1701.

18 (a) T. Bura, N. Leclerc, S. Fall, P. Lévêque, T. Heiser and R. Ziessel, Org. Lett., 2011, 13, 6030; (b) C. Ruiz, J. T. López Navarrete, M. C. Ruiz Delgado and B. Gómez-Lor, Org. Lett., 2015, 17, 2258.

19 M. C. Scharber, D. Mühlbacher, M. Koppe, P. Denk, C. Waldauf, A. J. Heeger and C. J. Brabec, Adv. Mater., 2006, 18, 789.

20 J. L. Brédas, D. Beljonne, V. Coropceanu and J. Cornil, Chem. Rev., 2004, 104, 4971.

21 I. Bulut, P. Lévêque, B. Heinrich, T. Heiser, R. Bechara, N. Zimmermann, S. Méry, R. Ziessel and N. Leclerc, J. Mater. Chem. A, 2015, 3, 6620.

22 S. Fall, L. Biniek, Y. Odarchenko, D. V. Anokhin, G. de Tournadre, P. Lévêque, N. Leclerc, D. A. Ivanov, O. Simonetti, L. Giraudet and T. Heiser, J. Mater. Chem. C, 2016, 4, 286.

23 Y. Zhou, C. Fuentes-Hernandez, J. Shim, J. Meyer, A. J. Giordano, H. Li, P. Winget, T. Papadopoulos, H. Cheun, J. Kim, M. Fenoll, A. Dindar, W. Haske, E. Najafabadi, T. M. Khan, H. Sojoudi, S. Barlow, S. Graham, J.-L. Brédas, S. R. Marder, A. Kahn and B. Kippelen, Science, 2012, 336, 327. 24 S. Fall, L. Biniek, N. Leclerc, P. Lévêque and T. Heiser, Appl. Phys. Lett., 2012, 101, 123301.

25 B. Kam, M. Li, Q. Zhang, F. Liu, X. Wan, Y. Wang, W. Ni, G. Long, X. Yang, H. Feng, Y. Zuo, M. Zhang, F. Huang, Y. Cao, T. P. Russel and Y. Chen, J. Am. Chem. Soc., 2015, 137, 3886.

26 Y. Lin, H. Fan, Y. Li and X. Zhan, Adv. Mater., 2012, 24, 3087. 